\title{
Memory test system for piston transient-state temperature measurement
}

\author{
Hui Dai ${ }^{1}$, Ronghua Huang ${ }^{1,}{ }^{,}$, Jie Tang ${ }^{2}$, Runwu Huang ${ }^{1}$ \\ ${ }^{1}$ State Key Laboratory of Coal Combustion, Huazhong University of Science and Technology, \\ Wuhan 430074, PR China \\ ${ }^{2}$ Geely Automobile Research Institute, Lingbo 310051, PR China \\ *Corresponding author. Email: rhhuang@hust.edu.cn
}

Key words: Piston transient-state temperature, Memory test system, Error

Abstract. The piston transient-state temperature measurement is very important for engine design and performance improvement. A memory test system (MTS) was designed for piston transient temperature measurement. Its transient error was inspected by a transient response test. Considering poor working conditions in engines, the steady and transient temperature was simultaneously measured on the same piston. Moreover, the measurement results for steady temperature were compared with them in literature [8]. The results show that MTS has very high precision and reliability, can detect the transient temperature in engines, and is competent in multi-condition test. MTS is an effective tool to measure piston temperature.

\section{Introduction}

Piston surface temperature during a working cycle is referred as to piston transient temperature in this paper. It reveals the real piston temperature revolution. By studying piston transient-state temperature, it is not difficult to find out whether the piston thermal load is high or not ${ }^{[1]}$, and how heat transfers in engines ${ }^{[2]}$. Furthermore, impingement of fuel on piston surface ${ }^{[3]}$ and deposits on combustion chamber surface ${ }^{[4]}$ may be identified. Thermal load, heat transfer, impingement of fuel on piston surface and deposits on combustion chamber surface has something to do with the reliability, economy, power and emission of engines. Thus, the piston transient-state temperature measurement is very important for engine design and performance improvement.

There are two methods to measure piston transient temperature, the phosphor thermometry and the electric thermometry. Phosphor thermometry is performed by exploiting the temperature-dependent luminescent properties of thermographic phosphors ${ }^{[5,6]}$. For this method, phosphorescence signal would be interfered by combustion luminosity and soot deposits might lead unsuccessful measurement. Thermocouples are used as sensors of electric thermometry. Whereas, how to send the signals out from engine is a fraught topic. One solution is to send the measured data out through wires mounted along the linkage mechanism ${ }^{[7]}$. Generally, fatigue failure of signal wires frequently occurs in linkage method. The telemetry system is also widely used, which sends data by means of wireless transmission technology ${ }^{[3]}$. However, wireless signals are interfered in the oil sump. In sum, these existing methods are not satisfactory. It is very difficult to get large amount of useful data.

This article introduces an apparatus designed for electric thermometry, denoted the Memory Test System (MTS). Functionally, the MTS mounted on piston-pin boss collects and stores signals from thermocouples. In the following contents, performance of the MTS will be inspected through a transient response test. Furthermore, simultaneous measurement of steady and transient temperature on the same piston is carried out to confirm its reliability in real engines. Meanwhile, the 
measurement result for steady temperature is compared with it in literature [8].

\section{System principles}

MTS adopts thermocouples as temperature sensors, and provides the cold-junction temperature signals for them. MTS processes signals of thermocouples and the cold-junction temperature, and stores them in it. After the experiment, these signals will be read out through serial ports for post-processing. There is no signal transmission out from the engine during the test.

MTS collects eight signals, $X_{0} \sim X_{7}$, of which there are two cold-junction compensation signals $\left(X_{0}, X_{1}\right)$ and six thermocouple signals $\left(X_{2} \sim X_{7}\right)$. Moreover, piston position signal is acquired. To collect these signals as quickly as possible with little power, MTS consists of six parts, compensation circuit, signal conditioning unit, position detection unit, clock, storage unit and control unit, as shown in figure 1.

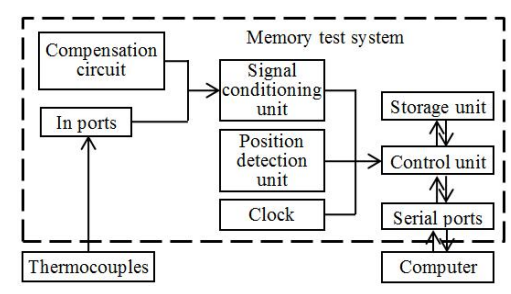

Fig. 1 Structure of system

\section{Compensation circuit}

The compensation circuit measures thermocouple cold-junction temperatures. A platinum resistor is used to measure the temperature near thermocouple cold-junctions, which is very close to cold-junction temperatures and regarded as it.

\section{Signal conditioning unit}

The signal conditioning unit receives signals of $X_{0} \sim X_{7}$. Since these signals are voltages of millivolt level, they will be magnified, smoothed, and converted into digital signals of 14 bits in the order from $X_{0}$ to $X_{7}$.

\section{Position detection unit}

Position detection unit consists of hall sensor and permanent magnet. Only when the hall sensor detects a magnetic field strong enough, would it output the digital signal 0 , otherwise, the hall sensor will output the digital signal 1 . The hall sensor is fixed on the piston, while the permanent magnet is mounted on the crankshaft. As the crankshaft rotates, the distance between the hall sensor and permanent magnet will change periodically. Accordingly, the magnetic field intensity sensed by the hall sensor will vary periodically. Thus, only when the crankshaft is at some certain crank angles, would the hall sensor output the digital signal 0 , otherwise, it will output the digital signal 1 .

The positon detection unit is used to confirm the crankshaft angle associate with piston transient-state temperature. By analyzing the signal of hall sensor, the original crankshaft angle is easy to determine during one engine operating cycle. Assuming that the rotating speed of engine stays the same during one engine operating cycle, it is not difficult to confirm the crankshaft angle.

Moreover, the position detecting unit is designed to control the working state of control unit. When the engine works, the control unit will calculate out the total number of the digital signals during one operating cycle, and then confirm the rotating speed of engine. If the rotating speed is 
high enough, the position detection unit will awaken control unit, conversely, the control unit will be inactive.

\section{Control unit}

The control unit is the brain of system. It not only controls the working state of system, but also regulates other components to finish data acquisition.

After power on, the control unit will determine the working state of system in accordance with the piston position unit. If the control unit is inactive according to the hall digital signal, the system will be inactive and consume little power, no data being acquired. On the contrary, the system will gather data and consume much power.

When the system is active, the control unit will read out the system time of clock and store it in the storage unit for working condition confirmation after the experiment. Afterwards, it will govern the signal conditioning unit and storage unit working to accomplish data collection. In order to collect as much data as possible for each signal during one operating cycle, every signal will be sampled continuously up to 2048 times.

\section{Experiments}

A transient response test was carried out to verify the system. Then, a bench test was implemented to verify MTS in engines.

\section{Transient response test}

A NI CDAQ-9174 card was used to provide the transient signals. Triangular waves of $25 \mathrm{~Hz}$, equivalent to the baseband of piston transient-state temperature under the rotating speed of 3000 $\mathrm{r} / \mathrm{min}$, were used as testing signals. Testing signals were firstly reduced to their $1 / 1000$, and then input to MTS. Input signal amplitudes were respectively $1-2 \mathrm{~V}, 9-10 \mathrm{~V}, 1.5-2 \mathrm{~V}$ and $8-10 \mathrm{~V}$, equivalent to $25-50^{\circ} \mathrm{C}, 225-250^{\circ} \mathrm{C}, 37.5-50^{\circ} \mathrm{C}$ and $200-250^{\circ} \mathrm{C}$ after being narrowed.

Results of only one channel were shown for that the results for every channel were more or less same. The arithmetic means of output signals within one hundred cycles were regarded as the measured values. The output signals were converted to temperatures and compared with the testing signals. Figure 2 shows the equivalent temperatures (ET) of testing signals and output signals. It can be found that not only the phases but also the values of the two signals are almost the same. It is to say that the system has very high precision and is qualified for piston transient-state temperature measurement when the rotating speed is no more than $3000 \mathrm{r} / \mathrm{min}$.

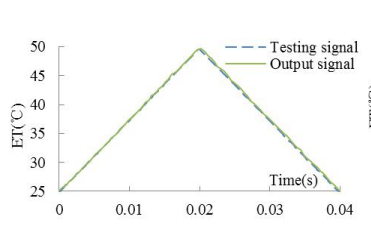

a) $1-2 \mathrm{~V}$

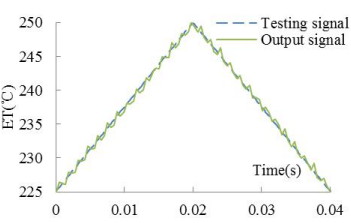

b) $9-10 \mathrm{~V}$

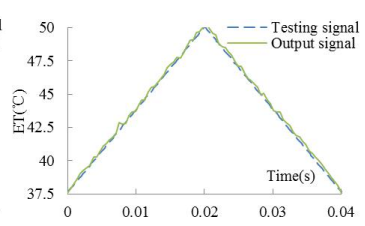

c) $1.5-2 \mathrm{~V}$

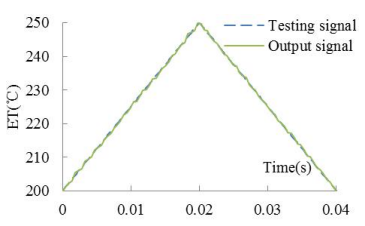

d) $8-10 \mathrm{~V}$

Fig. 2 Equivalent temperatures of testing signal and output signal

\section{Bench test}

A Cummins diesel engine, model 6BT5.9, was used to conduct the experiment. 5 points on the piston were chosen to mount sensors, the center and bottom of combustion chamber, piston crown and first ring shore. The above 5 points are on the same plane, as numbered in figure 3 . 


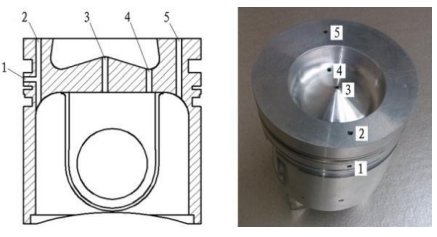

Fig. 3 Locations of measuring points

Omega TT-K-40 thermocouples, the diameter of temperature measuring end less than $0.1 \mathrm{~mm}$, were used as temperature sensors for MTS. Their errors were less than $1.2^{\circ} \mathrm{C}$. In this test, measuring point 2 and 3 were used to measure the transient-state temperatures, while the others were for steady-state temperatures. For measuring points of steady temperature, the thermal-junction of thermocouple was embedded in a small plug $(\varphi 3 \mathrm{~mm} \times 7 \mathrm{~mm})$ with Huitian $\mathrm{C} 2$ heat-conducting glue. Then the plug was pounded into the mounting hole from the top of piston, and the mounting hole was filled with heat-conducting glue from the bottom of piston, as shown in figure 4 . The thermal-junction of thermocouple was about $2 \mathrm{~mm}$ away from the top of piston. For measuring points of transient temperature, temperature measuring end was directly embedded in piston with $\mathrm{C} 2$ glue, leaving the distance to the surface within $0.2 \mathrm{~mm}$.

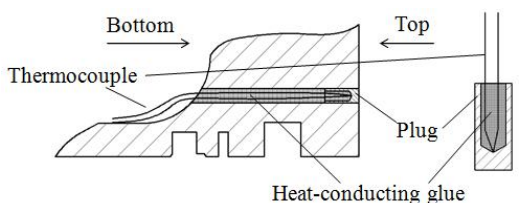

a) Measuring point of steady temperature

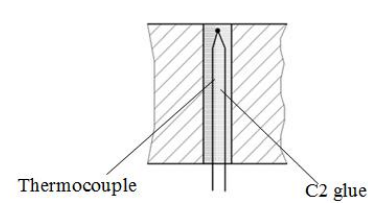

b) Measuring point of transient temperature

Fig. 4 Thermocouple installation schematic

In this test the acquisition speed of MTS was kept at two samples per crankshaft angle. The temperature of coolant and oil were almost the same with them in literature [8]. The arithmetic mean of 2048 samples was regarded as the measured value for measuring point of steady-state temperature. Figure 5 shows the steady temperatures for different rotating speeds of this paper (case one) compared with them in literature [8] (case two). As is shown in figure 5, the difference between them are very small, no more than $5{ }^{\circ} \mathrm{C}$, which means that MTS can work reliably and acquire the real piston steady-state temperature, and is competent in multi-condition test.

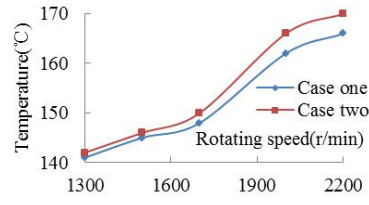

a) Point 1

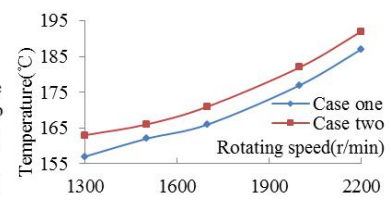

b) Point 4

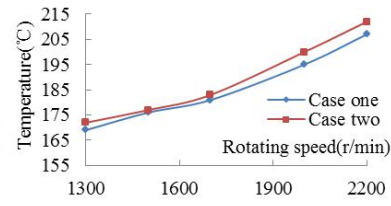

c) Point 5

Fig. 5 Steady-state temperature

For transient temperature, the rotating speed was assumed the same within one cycle. Figure 5 shows the transient temperature revolutions within one cycle at rotating speed of $1300 \mathrm{r} / \mathrm{min}$ and torque of 140 N.m. It is easy to find that the temperature range of point 2 and 3 are respectively $216 \sim 233^{\circ} \mathrm{C}$ and $233 \sim 252^{\circ} \mathrm{C}$, much higher than in literature [8]. Meanwhile, the crankshaft angle related to the lowest and highest temperature are respectively $398^{\circ} \mathrm{CA}$ and $482^{\circ} \mathrm{CA}$, much later than the phase of combustion. The reason may be that the gas with high temperature and high pressure tears $\mathrm{C} 2$ glue and flows into the gap of $\mathrm{C} 2$ glue, leaving thermocouples being packaged by gas and heated to much higher temperature. However, the specific heat of gas is so small that it takes too much time to heat thermocouples, which means that the heat transfer is slower than 
combustion. Thus, it is necessary to keep the temperature measuring end cling to the piston. On the whole, MTS can detect the transient temperature in engines.

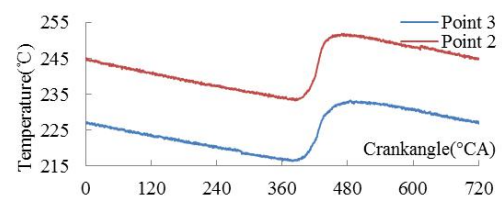

Fig. 6 Transient temperature revolutions within one cycle

\section{Summary}

A memory test system was designed to measure piston transient-state temperature. Through a transient response test, it is found that the system has very high precision and is qualified for piston transient-state temperature measurement when the rotating speed is no more than $3000 \mathrm{r} / \mathrm{min}$. The steady and transient temperatures were simultaneously measured on the same piston. Moreover, the measurement results for steady-state temperature were compared with them in literature [8].Conclusions can be drawn that MTS can work reliably and detect the transient temperature in engines, and is competent in multi-condition test.

In short, MTS is an effective tool to measure transient-state temperature under bad environment like piston. With the aid of MTS, accurate piston temperature can be obtained.

\section{References}

[1] F.S. Silva. Fatigue on engine pistons- A compendium of case studies [J]. Engineering Failure Analysis, 2006, 13:480-492

[2] A.J. Torregrosa, V. Bermudez, P. Olmesa, Et al.. Experimental assessment for instantaneous temperature and heat flux measurements under diesel motored engine conditions [J]. Energy Conversion and Management, 54(2012):57-66

[3] Scott A. Miers, Carl L. Anderson, Jason R. Blough, Et al.. Impingement Identification in a High Speed Diesel Engine Using Piston Surface Temperature Measurements. SAE Technical, 2005-01-1909

[4] Orgum Güralp, Mark Hoffman, Et al.. Thermal Characterization of Combustion Chamber Deposits on the HCCI Ehgine Piston and Cylinder Head Using Instantaneous Temperature Measurements. SAE International, 2009-01-0668

[5] Julian T. Kashdan, Gilles Bruneaux. Laser-induced phosphorescence measurements of combustion chamber surface temperature on a single-cylinder diesel engine. SAE International, 2011-01-2049

[6] Tobias Husberg, Savo Gjirja, Ingemar Denbratt, Et al.. Piston temperature measurement by use of thermographic phosphors and thermocouples in a heavy-duty diesel engine run under partly premixed conditions. SAE Technical, 2005-01-1646

[7] Kukwon Cho, Ronald O. Grover, Dennis Assanis, Et al.. Combing instantaneous temperature measurements and CFD for analysis of fuel impingement on the DISI engine piston top[J]. Journal of Engineering for Gas Turbines and Power, 2010, 132(7), 072805

[8] Pengen Gao, Hui Dai, Ronghua Huang, et al.. Study on the relationship between piston steady-state temperature and operation condition of diesel engine [J]. Journal of Huangzhong University of Science and Technology (natural science edition), 44(2016):98-102 